\title{
Markers of airway inflammation and airway hyperresponsiveness in patients with well-controlled asthma
}

\author{
J.D. Leuppi*, C.M. Salome*, C.R. Jenkins*, H. Koskela", J.D. Brannan\#, S.D. Anderson\#, \\ M. Andersson*, H.K. Chan ${ }^{\#}$, A.J. Woolcock*,
}

\begin{abstract}
Markers of airway inflammation and airway hyperresponsiveness in patients with wellcontrolled asthma. J.D. Leuppi, C.M. Salome, C.R. Jenkins, H. Koskela, J.D. Brannan, S.D. Anderson, M. Andersson, H.K. Chan, A.J. Woolcock. C ERS Journals Ltd 2001.

ABSTRACT: In steroid-naïve asthmatics, airway hyperresponsiveness correlates with noninvasive markers of airway inflammation. Whether this is also true in steroid-treated asthmatics, is unknown.

In 31 stable asthmatics (mean age 45.4 yrs, range 22-69; 17 females) taking a median dose of $1,000 \mu \mathrm{g}$ inhaled corticosteroids (ICS) per day (range 100 $3,600 \mu \mathrm{g} \cdot \mathrm{day}^{-1}$ ), airway responsiveness to the "direct" agent histamine and to the "indirect" agent mannitol, lung function (forced expiratory volume in one second (FEV1), forced vital capacity (FVC), peak expiratory flow (PEF)), exhaled nitric oxide (eNO), and number of inflammatory cells in induced sputum as a percentage of total cell count were measured.

Of the 31 subjects, 16 were hyperresponsive to mannitol and 11 to histamine. The dose-response ratio (DRR: \% fall in FEV1/cumulative dose) to both challenge tests was correlated $(\mathrm{r}=\mathbf{0 . 5 9}, \mathrm{p}=\mathbf{0 . 0 0 0 4})$. However, DRR for histamine and DRR for mannitol were not related to basic lung function, eNO, per cent sputum eosinophils and ICS dose. In addition, NO was not related to basic lung function and per cent sputum eosinophils.

In clinically well-controlled asthmatics taking inhaled corticosteroids, there is no relationship between markers of airway inflammation (such as exhaled nitric oxide and sputum eosinophils) and airway responsiveness to either direct (histamine) or indirect (mannitol) challenge. Airway hyperresponsiveness in clinically well-controlled asthmatics appears to be independent of eosinophilic airway inflammation.

Eur Respir J 2001; 18: 444-450.
\end{abstract}

\begin{abstract}
*Institute of Respiratory Medicine, University of Sydney, New South Wales, and ${ }^{\#}$ Dept of Respiratory Medicine, Royal Prince Alfred Hospital, Camperdown, New South Wales, Australia. ${ }^{\dagger}$ Died February 17, 2001.
\end{abstract}

Correspondence: J.D. Leuppi, Dept of Internal Medicine, University Hospital, CH-4031 Basel, Switzerland.

Fax: 41612655353

Keywords: Airway hyperresponsiveness, airway inflammation, asthma, exhaled nitric oxide, sputum, steroids.

Received: June 282000

Accepted after revision March 202001

Supported by the National Health and Medical Research Council, the Australian ARDS Association, and a grant-in aid from Rhone-Poulenc Rorer, Australia. J. Leuppi was funded by Swiss National Science Foundation; NovartisFoundation, Switzerland; and Swiss Respiratory Society.
The clinical management of asthmatic patients depends on monitoring lung function and symptoms $[1,2]$. However, airway inflammation can be present in asthmatic patients who are clinically well-controlled [3], suggesting that these measurements may not be sensitive enough to reflect the extent of airway inflammation.

Airway inflammation is a characteristic feature of asthma, and treatment with inhaled corticosteroids (ICS) is commonly prescribed as first-line therapy in mild, as well as moderate and severe asthma [4]. Airway hyperresponsiveness (AHR), assessed by bronchial challenge, is also a characteristic feature of asthma and seems to be related to airway inflammation $[5,6]$. This relationship can be shown in steroid-naïve adults with "direct" challenges such as methacholine [5], as well as in children with "indirect" challenges such as hypertonic saline [6]. Chronic treatment with ICS reduces responsiveness to both hypertonic saline and histamine [7], although the time course to achieve this differs.

Airway inflammation can also be measured indirectly by counting the numbers of inflammatory cells in sputum [8]. Sputum collected from patients with an exacerbation of their asthma contains a very high number of eosinophils [9], but this number is reduced following ICS treatment [10], suggesting sputum eosinophil numbers may also be useful in monitoring asthma severity.

Airway inflammation may also be reflected by the levels of exhaled nitric oxide (eNO). Exhaled NO is increased during asthma exacerbations [11], and reduced in subjects taking ICS [11, 12]. These data suggest that eNO may be used as a marker of airway inflammation to monitor asthma.

This study examined whether markers of airway inflammation, as measured by inflammatory cells in induced sputum and eNO, were related to airway responsiveness, as measured by sensitivity to histamine (a pharmacological agent) and mannitol (an osmotic agent) in patients who were stable and wellcontrolled upon treatment with steroids.

\section{Methods}

\section{Subjects}

Fifty subjects were recruited. Data are reported for the 31 subjects from whom a sputum sample was 
obtained. These 31 subjects (17 females), who were using ICS to control their asthma symptoms, met the American Thoracic Society criteria for asthma [13], had a history of wheezing and chest tightness, and were previously diagnosed by a physician as having asthma. These subjects were recruited from the Asthma Clinic of the Royal Prince Alfred Hospital, Sydney, Australia. Information on atopic status was available for 27 subjects, all of whom were atopic. Nine subjects were exsmokers. The mean age of the subjects was 45.4 (range: 22-69) yrs, the mean duration of their asthma was 24.9 (range: 2.5-60) yrs and the mean duration of their ICS use was 6.7 (range: 1-18) yrs. Nine subjects were using fluticasone, 16 budesonide and six beclomethasone, at a mean daily dose of $1,284 \mu \mathrm{g} \mathrm{ICS} \cdot$ day $^{-1}(95 \%$ confidence interval (CI): 1,029-1,539). Four subjects were using longacting $\beta$-agonists (LABA) and all used short-acting $\beta$-agonists when needed. All subjects were clinically stable. In the 4 weeks before the study, they had asthma symptoms no more than twice a week, did not wake up at night because of asthma and had no respiratory tract infection. They had no changes in their dose of ICS in the last 4 weeks and the mean changes in dose of ICS were $<1,000 \mu \mathrm{g}$ daily in the last 3 months. Exclusion criteria were current smoking and the use of oral steroids within the previous 6 months.

The study was approved by the Central Sydney Area Health Service Ethics Committee. The trial was carried out under the Clinical Trial Notification Scheme of the Therapeutics Goods Administration of Australia (CTN No. 1997/373). All subjects signed a consent form prior to commencement of the study.

\section{Study design}

This was a cross-sectional study. Subjects were asked to come for two study visits within 2 weeks (7-14 days between visits). They were asked to refrain from taking short-acting $\beta$-agonists for $6 \mathrm{~h}$, LABA for $24 \mathrm{~h}$ and antihistamines for 3 days before each study day. No ICS were taken on the day of the study. On arrival, the clinical diagnosis of asthma was confirmed by a staff physician by examination and history. On the first visit, an "indirect" challenge with mannitol was performed and on the second day a "direct" challenge with histamine. Exhaled NO and spirometry were measured before the challenge tests on both days, and sputum was collected during and/or after the mannitol challenge. Subjects were also asked to record in a diary card, their asthma symptoms, bronchodilator use and peak expiratory flow (PEF) twice daily before inhaling their asthma medication for the 4 weeks of the study.

\section{Lung function measurements}

Spirometry was performed using a MicroLoop II Spirometer (Micro Medical Ltd, Kent, UK). Forced expiratory volume in one second (FEV1) was used as an index of airway calibre. Forced expiratory manoeuvres were repeated until two readings of FEV1 within $100 \mathrm{~mL}$ were obtained, the largest of which was used in analyses. Values for FEV1 and forced vital capacity (FVC) were recorded as a percentage of the predicted values of KNUDSON et al. [14].

\section{Bronchial responsiveness}

Histamine challenge. A bronchial provocation test (BPT) with histamine was administered to all subjects using the rapid method [15]. Histamine diphosphate (ICN Pharmaceuticals Inc., Costa Mesa, CA, USA) was administered using DeVilbiss No. 45 hand-held nebulizers (DeVilbiss Health Care Inc., Somerset, PA, USA), in doubling doses 0.03-3.9 $\mu \mathrm{mol}$. The test was stopped if FEV1 fell by $\geqslant 20 \%$. Salbutamol aerosol was administered to aid recovery when necessary. The dose of histamine which provoked a 20\% fall in FEV1 (PD20) was estimated by interpolation. The dose-response ratio (DRR) was calculated for all subjects as the percentage fall in FEV1 at the last dose, divided by the total dose administered $[16,17]$. AHR was defined as PD20 $\leqslant 3.9 \mu \mathrm{mol}$ histamine or a DRR $>8.1$.

Mannitol capsule challenge. A BPT with a dry powder of mannitol was administered to all subjects using the protocol previously described by ANDERSON et al. [18]. In brief, a noseclip was applied and subjects then performed the challenge with doses consisting of 0 (empty capsule acting as a placebo), 5, 10, 20, 40, 80, 160,160 and $160 \mathrm{mg}$ of mannitol via a Halermatic ${ }^{\mathrm{TM}}$ (Rhône Poulenc Rorer, Collegeville, PA, USA). The $80 \mathrm{mg}$ and $160 \mathrm{mg}$ were given in multiple doses of $40 \mathrm{mg}$ capsules. At least two FEV1 manoeuvres were performed $60 \mathrm{~s}$ after each dose and the highest FEV1 was used in the calculation. The FEV1 value measured after the $0 \mathrm{mg}$ capsule was taken as the prechallenge FEV1 and used to calculate the percentage decrease in FEV1 in response to the mannitol challenge. If the subject had a $>10 \%$ fall in FEV1 in response to a single dose, the same dose was repeated for reasons of safety. The challenge ceased when a $15 \%$ fall in FEV1 was documented or a cumulative dose of $635 \mathrm{mg}$ had been administered. Salbutamol aerosol was administered to aid recovery when necessary. DRR was calculated for all subjects. The provocative dose of mannitol causing a 15\% fall in FEV1 (PD15) was calculated by linear interpolation of the relationship between the percentage fall in FEV1 and the cumulative dose of mannitol required to provoke this fall. AHR was defined as a PD15 $\leqslant 635 \mathrm{mg}$ of mannitol equivalent to a DRR $>0.023 \%$ fall in FEV $1 \cdot \mathrm{mg}^{-1}$ of mannitol delivered by inhalation.

\section{Nitric oxide measurement}

Mixed expired NO was measured using a modification of the method of Massaro et al. [11, 19]. The measurement was performed with the subject standing, without wearing a noseclip. The patient took a deep breath and exhaled for $>5-15 \mathrm{~s}$ to residual 
volume into an NO impermeable polyethylene bag (Scholle Industries Pty Ltd, Elizabeth West, Australia). The exhaled flow, measured by a rotameter (Dwyer Flowmeter Model VFASS-25, AMBIT Instruments Pty Ltd, Parramatta, Australia), was $10 \mathrm{~L} \cdot \mathrm{min}^{-1}$ at a mouth pressure $>20 \mathrm{cmH}_{2} \mathrm{O}$. The exhaled gas from a single breath was analysed within an hour, using a chemiluminescent analyser (Model 42C, Thermo Environmental Instruments, Franklin, MA, USA), which has a lower limit of detection of 1 part per billion (ppb). Ambient NO in the laboratory was measured at the time of testing.

\section{Sputum collection}

Sputum collection was carried out in conjunction with the mannitol challenge. If subjects had to cough during the mannitol challenge, they were asked to spit whatever was produced into a sterile container. At the end of the mannitol challenge, subjects were asked to cough and spit whatever was produced. All subjects rinsed their mouths with water at each collection point to remove any food particles and reduce salivary contamination. All specimens were retained for later examination under the microscope, even if there were no obvious sputum plugs.

\section{Sputum preparation and differential cell count}

Sputum was processed as described by Pizzichini et al. [20]. Briefly, sputum plugs were picked up and four-times the volume of diluted Sputolysin (0.1\%) (Sputolysin Reagent, Calbiochem, Corp., San Diego, CA, USA) was added. The samples were placed in a shaking water bath $\left(37^{\circ} \mathrm{C}\right)$ for $30 \mathrm{~min}$ and then filtered through $50 \mu \mathrm{m}$ nylon gauze. The slides were assessed for quality before they were counted, and slides with $>20 \%$ squamous cells were rejected. A total cell count was performed and cyto-centrifuge slides were prepared (Shandon Cytospin II, Sewickery, PA, USA). The inflammatory cells were expressed as a percentage of the total inflammatory cell count (400 cells) on slides fixed with methanol and stained with MayGrunwald Giemsa.

\section{Peak flow home monitoring}

Subjects were asked to perform PEF measurements while standing, twice a day, before inhaling their medication, for 4 weeks. The subjects blew three times into the peak flow meter (mini-Wright, Clement Clarke International Ltd, Essex, UK) and recorded the best of three values. The lowest PEF reading for the last of 4 weeks was calculated as a percentage of the best peak flow value achieved during the 4-week period [21, 22].

\section{Symptoms score}

Subjects were asked to fill in a diary card and to tick the level of their asthma symptoms. Morning and evening symptom scores were combined to produce a score of $0-8$ ( 0 being symptom free and 8 having maximum symptoms).

\section{Statistical analysis}

Analysis of PD15 mannitol, PD20 histamine, DRR values of both challenge tests, eNO, eosinophils and neutrophils were carried out on log transformed data. Summary values for DRR, eNO, eosinophils and neutrophils are geometric means, with their 95\% CIs. Summary values for all other parameters are arithmetic means and $95 \%$ CIs. The agreement between histamine and mannitol for classifying subjects with AHR was determined by Chi-squared analysis. Relationships were determined using the Pearson correlation for normally distributed variables, and nonparametric tests (Spearman's rho-tests) for all other variables. Significance was accepted at the 5\% level.

\section{Results}

Of the original 50 subjects with well-controlled asthma recruited for this study, 31 were able to produce sputum giving a success rate of $62 \%$. The baseline characteristics of subjects who could and could not produce sputum did not differ significantly (table 1). The values for spirometry were in the normal predicted range. There was no significant difference in FEV1 \% predicted, or in the level of eNO between the two study days. However, there was a small but significant difference in FVC \% pred $(86.8$ (95\% CI: 81.4-92.2) versus 84 (95\% CI: 78.8-89.2); $\mathrm{p}=0.03)$ and PEF \% pred values (84.6 (78.8-90.3) versus 80 (74.7-85.1); $\mathrm{p}=0.006)$.

Of these 31 well-controlled asthmatics, 11 were hyperresponsive to histamine (PD20 histamine) and 16 to mannitol (PD15 mannitol). The DRR for histamine was significantly related to the DRR for mannitol ( $r=0.59, p=0.0004)$ (fig. 1). There was considerable overlap in airway responsiveness in subjects with and without sputum. There was significant agreement between the two challenge tests with respect to the classification of responders (PD20 histamine, PD15 mannitol) and nonresponders both for the group as a whole (Chi-squared: 11.66, $\mathrm{p}=0.0006$ ) and for the subset of subjects with sputum (Chi-squared: 4.09, $\mathrm{p}=0.04)$. There were significant correlations between DRR measurements both for the group as a whole $(\mathrm{r}=0.63, \mathrm{p}<0.0001)$ and for the group with sputum $(\mathrm{r}=0.61, \mathrm{p}=0.00031)$. However, there was no significant relationship between FEV1 \% pred and the DRR histamine or the DRR mannitol (table 2).

There was a weak correlation between sputum neutrophils and DRR for mannitol ( $\mathrm{r}=0.36, \mathrm{p}=0.046)$. With this exception, there was no relationship demonstrated between either the inflammatory cells collected in the sputum or eNO and airway responsiveness to either histamine or mannitol (table 2). Figure 2 shows the relationship between DRR for mannitol and sputum eosinophils. There were 15 
Table 1. - Baseline characteristics of subjects from whom sputum was obtained for analysis of inflammatory cell numbers and of subjects who were unable to produce sputum

\begin{tabular}{|c|c|c|c|}
\hline & Subjects with sputum & Subjects without sputum & p-value \\
\hline Subjects $n$ & 31 & 19 & \\
\hline Sex M:F & $15: 16$ & $10: 9$ & \\
\hline Age yrs & $45.7(40.6-50.8)$ & $42.0(35.1-48.7)$ & 0.38 \\
\hline Atopic n $(\%)$ & $\begin{array}{c}26(100) \\
\text { (no data } n=4)\end{array}$ & $\begin{array}{c}13(81) \\
\text { (no data } n=3 \text { ) }\end{array}$ & \\
\hline Daily ICS dose (BDP equivalent) & $1402(1092-1711)$ & $1397(1045-1749)$ & 0.99 \\
\hline Symptom score & $3.5(3.2-4.2)$ & $3.1(2.9-4.2)$ & 0.32 \\
\hline Baseline FEV $1 \%$ pred & $82.9(75.9-89.8)$ & $90.1(81.7-98.5)$ & 0.19 \\
\hline Baseline FVC \% pred & $86.8(81.4-92.2)$ & $95(88.5-98.6)$ & 0.06 \\
\hline Baseline PEF \% pred & $84.6(78.8-90.3)$ & $88.9(79.4-98.4)$ & 0.40 \\
\hline PEF lowest \% best & $85.5(92.9-88)$ & $86(82.5-89.5)$ & 0.81 \\
\hline Exhaled NO ppb & $19.5(15.9-23.9)$ & $15.8(13.1-19.1)$ & 0.17 \\
\hline DRR mannitol $\%$ fall $\mathrm{FEV} 1 \cdot \mathrm{mg}^{-1}$ & $0.063(0.044-0.090)$ & $0.061(0.038-0.101)$ & 0.94 \\
\hline AHR to mannitol $\mathrm{n}$ & 16 & 8 & 0.87 \\
\hline DRR histamine $\%$ fall $\mathrm{FEV} 1 \cdot \mu \mathrm{mol} ;+3$ & $8.68(5.56-13.56)$ & $7.35(5.03-10.74)$ & 0.60 \\
\hline AHR to histamine $n$ & 11 & 4 & 0.83 \\
\hline Max dose mannitol mg & $341(244-478)$ & $321(205-503)$ & 0.83 \\
\hline Mannitol max $\%$ fall & $14.8(12.4-17.1)$ & $13.8(10.7-16.9)$ & 0.62 \\
\hline Eosinophils \% & $2.01(1.1-3.7)$ & & \\
\hline Neutrophils \% & $15.2(10.6-21.7)$ & & \\
\hline Macrophages \% & $70.3(56.6-74.6)$ & & \\
\hline Lymphocytes \% & $0.9(0.6-3.3)$ & & \\
\hline
\end{tabular}

Data are presented as geometric mean (95\% confidence interval (CI)) for dose-response ratio (DRR), exhaled nitric oxide (eNO), eosinophils and neutrophils; and arithmetic mean $(95 \% \mathrm{CI})$ for all other parameters unless otherwise stated. M: male; F: female; ICS: inhaled corticosteroids; BDP: beclomethasome diproprionate; FEV1: forced expiratory volume in one second; FVC: forced vital capacity; PEF: peak expiratory flow; AHR: airway hyperresponsiveness; ppb: parts per billion. DRR is taken as the $\%$ fall in FEV 1 at the last dose per cumulative dose (for histamine, +3 is added).

subjects with sputum eosinophils $>2.5 \%$ of the total cells, but these subjects did not differ from those with $<2.5 \%$ eosinophils in either histamine DRR ( $\mathrm{p}=0.36)$

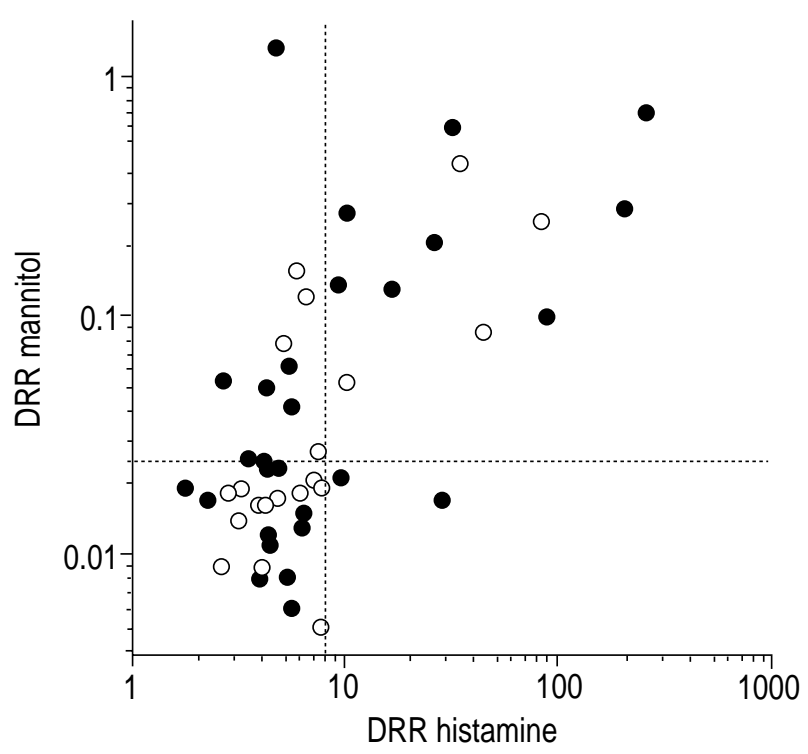

Fig. 1.-The relationship between dose-response ratio (DRR) for histamine, as per cent fall in forced expiratory volume in one second $\left(\mathrm{FEV}_{1}\right)$ per $\mu \mathrm{mol}$ histamine administered, plus 3 , and DRR for mannitol, as per cent fall FEV1 per mg mannitol administered for 50 subjects originally recruited into the study. values for the subjects from whom sputum was obtained; $\bigcirc$ : subjects who were unable to produce sputum. The dotted vertical and horizontal lines show the cutpoints for defining airway hyperresponsiveness to histamine and mannitol. or mannitol DRR ( $\mathrm{p}=0.21)$. Mast cells were detectable in the sputum of only four subjects; two of these were hyperresponsive to histamine and three were hyperresponsive to mannitol. Exhaled NO was not significantly correlated with sputum eosinophils ( $\mathrm{r}=0.23$, $\mathrm{p}=0.21)$ or neutrophils $(\mathrm{r}=-0.03, \mathrm{p}=0.75)$.

Table 2. - Relationship between responsiveness to histamine and mannitol as expressed by the dose-response ratio (DRR) and lung function variables, inhaled corticosteroid (ICS) dose, the concentration of exhaled nitric oxide (eNO) and the percentage of cells in sputum

\begin{tabular}{|c|c|c|c|c|}
\hline & \multicolumn{2}{|c|}{ DRR mannitol } & \multicolumn{2}{|c|}{ DRR histamine } \\
\hline & $\mathrm{r}$ & p-value & $\mathrm{r}$ & $\mathrm{p}$-value \\
\hline FEV $1 \%$ pred & -0.292 & 0.11 & -0.213 & 0.26 \\
\hline FVC \% pred & -0.230 & 0.22 & -0.032 & 0.88 \\
\hline PEF \% pred & -0.083 & 0.137 & -0.108 & 0.57 \\
\hline ICS dose $\mu \mathrm{g}$ & 0.124 & 0.51 & 0.162 & 0.39 \\
\hline Exhaled NO ppb & 0.243 & 0.19 & 0.157 & 0.41 \\
\hline Sputum eosinophils \% & 0.23 & 0.22 & -0.24 & 0.24 \\
\hline Sputum neutrophils \% & 0.36 & 0.046 & 0.3 & 0.15 \\
\hline Sputum lymphocytes \% & -0.24 & 0.32 & 0.10 & 0.30 \\
\hline Sputum macrophages $\%$ & -0.239 & 0.20 & -0.1 & 0.31 \\
\hline Sputum mast cells \% & -0.02 & 0.90 & -0.02 & 0.90 \\
\hline
\end{tabular}

r: Pearson correlation coefficient; FEV1: forced expiratory volume in one second; FVC: forced vital capacity; PEF: peak expiratory flow; ppb: parts per billion. DRR is taken as the maximal $\%$ fall in FEV 1 per cumulative dose (for histamine, +3 is added). 


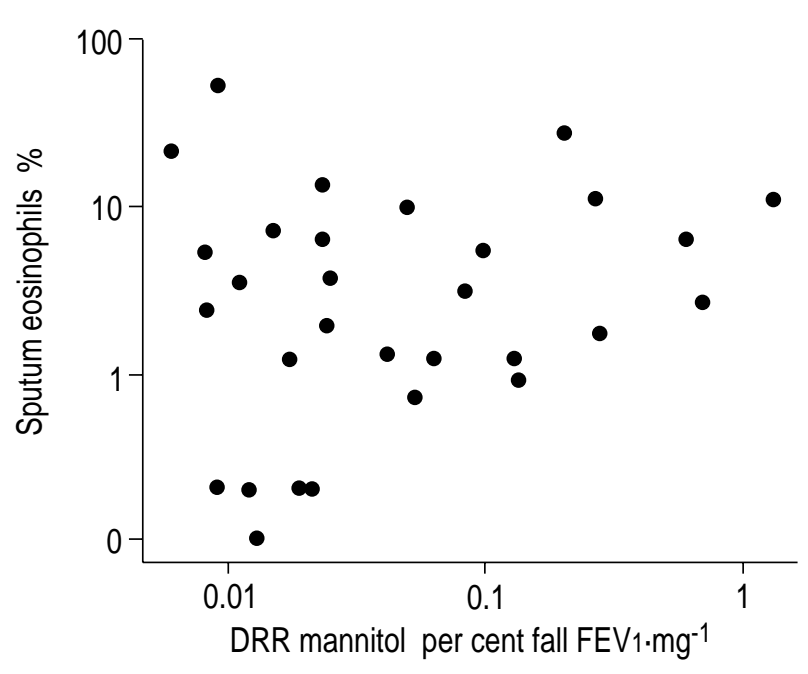

Fig. 2. - The relationship between the dose-response ratio (DRR) for mannitol, as per cent fall in forced expiratory volume in one second (FEV1) per mg mannitol administered, and sputum eosinophils, as a percentage of the total inflammatory cells counted. The correlation was not statistically significant using either parametric (Pearson's $\mathrm{r}=0.25, \mathrm{p}=0.20)$ or nonparametric $\left(\mathrm{r}_{\mathrm{s}}=0.14, \mathrm{p}=0.48\right)$ analyses.

\section{Discussion}

This study has shown that in steroid-treated stable asthmatics, there is no relationship between indirect markers of airway inflammation, such as eNO or sputum eosinophils, and spirometry or airway responsiveness. Significant relationships were found only between the airway responsiveness to histamine and to mannitol and the sputum neutrophils and airway responsiveness to mannitol.

Sputum was successfully collected from 31 of a possible 50 subjects. The failure to collect sputum successfully from all subjects may have related to their well-controlled asthma. Mannitol is acting as a hyperosmolar stimulus to the airways in the same manner as hypertonic saline in terms of AHR [23]. While no formal comparison has been made between collecting sputum with mannitol and hypertonic saline, no differences have been noted between normal and hypertonic saline, suggesting that increasing the osmolarity itself does not affect the cell number [24]. While the authors may have been even more successful using a wet aerosol challenge, a success rate of $60 \%$, which is similar to that reported by others [8], was obtained.

The present study appears to be the first one looking for a relationship between indirect markers of airway inflammation in well-controlled asthmatics who had been using ICS for several years. In this population, no clinically significant relationship could be found between markers of airway inflammation such as eNO or sputum eosinophils, and lung function values or airway responsiveness. In nonasthmatic people, sputum eosinophils can be up to $2.5 \%$ of the total cell count, especially when atopic subjects are included $[3,25]$. A mean value of $2.0 \%$ eosinophils was found in this population of stable asthmatics, which is within the normal range. Treatment with ICS decreases the percentage of sputum eosinophils and reduces the release of cytokines such as interleukin-5 and granulocyte-macrophage colony-stimulating factor [26]. CRIMi et al. [27] also found no significant correlation between the degree of airway responsiveness to the direct BPT methacholine and the numbers of inflammatory cells in sputum, bronchoalveolar lavage or bronchial biopsy.

However, a weak, but significant, correlation between sputum neutrophils and DRR for mannitol was found. These findings are supported by WARK et al. [28], who found that sputum eosinophils are highest in asthmatics not using ICS, and neutrophils are higher in subjects using ICS. There is also some evidence that isolated sputum neutrophilia does not respond to treatment with corticosteroids [29].

Airway inflammation may also be reflected by the levels of eNO. Exhaled NO is increased in steroidnaïve asthmatics and reduced in those after taking ICS [12]. The mean eNO levels in the present study's population was in the high normal range, based on a population study in the authors' region [19]. The eNO level found in the present study is similar to that found in the study of JATAKANON et al. [30], in which eNO was reduced with their highest dose of budesonide $(1,600 \mu \mathrm{g})$ from $40.9 \mathrm{ppb}$ to $18.3 \mathrm{ppb}$.

In steroid-naïve asthmatics, there is a significant relationship between eNO and provocative concentration causing a $20 \%$ fall in FEV1 (PC20) methacholine [5], PC20 histamine [31] or sputum levels of eosinophils [5]. Steroids decrease the level of eNO, probably by inhibiting the inducible NO synthase [12]. AHR also improves with ICS treatment by an effect on different infiltrative and resident cells [7, 32]. Looking at all these data, it could be expected that a relationship between these markers of airway inflammation would persist even under ICS treatment. However, VAN RENSEN et al. [33] found no relationship between changes in PC20 methacholine, sputum eosinophils and eNO after 4 weeks of ICS treatment, although all these measurements showed a significant improvement. Furthermore, Lim et al. [34] did not find a significant relationship between eNO and mucosal eosinophils (mucosal biopsy) in ICS-treated, as well as ICS-naïve asthmatic patients. It is possible that differences in the dose and duration of ICS treatment may have differential effects on inflammation, eNO and responsiveness, and thus reduce the likelihood of finding a relationship between them.

In the present study, there was a good relationship between responses to the two challenge tests, although 16 subjects were hyperresponsive to mannitol and only 11 to histamine. Cut-off points for defining AHR are widely used and established [35]. However, these cut-off points are sometimes arbitrary and therefore, may not reflect any real biological difference between subjects thus defined as normal or abnormal. Furthermore, the level of measurement error (usually at least \pm one doubling dose) would mean that subjects with mild hyperresponsiveness could be classified wrongly to either the positive or negative AHR group $[15,36]$. For this reason, it is better to use a continuous variable, such as DRR, to explore the relationship between the two tests. Using 
this index of responsiveness, a significant relationship was demonstrated between sensitivity to histamine and mannitol. The present findings are supported by other studies, in which significant relationships between histamine and hyperosmolar saline were found for patients taking ICS [7].

It is thought that as a "direct agent", histamine acts at specific receptors on bronchial smooth muscle to cause contraction. By contrast, mannitol is an osmotic agent and acts "indirectly" to release mediators from inflammatory cells in the airways [7, 37]. These mediators, which appear to include histamine and leukotrienes [38, 39] then act on smooth muscle to cause contraction. The finding of a relationship between responsiveness to histamine and mannitol could simply be that histamine is common to both challenges. The fact that more subjects were responsive to mannitol than histamine could be due to leukotrienes being released in response to mannitol, thus providing a potent stimulus to airway narrowing. There was no relationship between airway responsiveness and baseline spirometry, suggesting that in these subjects, airway calibre explains none or only a small proportion of the variation in the response to either histamine or mannitol. Similarly, airway inflammation, as measured by eNO or sputum eosinophils, may explain only a small amount of the variation in AHR. It could be argued that eNO and sputum eosinophils may more closely reflect cells in the lumen and the superficial epithelium, but not the submucosa. Hence, the element of AHR which might result from airway wall thickening or structural changes beneath the epithelium [40] may relate poorly with measurements from the airway lumen such as eNO and sputum eosinophils, which are more sensitive to the effects of ICS. However, it is possible that the small sample size in the present study reduced the power of the study to detect significant relationships between sputum inflammatory cells and airway responsiveness.

In conclusion, in subjects with well-controlled asthma, taking inhaled steroids, there was no relationship between airway inflammation, measured either by sputum eosinophils or exhaled nitric oxide, and airway responsiveness measured by either histamine or mannitol. The relationship between responsiveness to mannitol and sputum neutrophils, while weak, was significant in this small number of subjects. This finding warrants further investigation because more subjects were hyperresponsive to inhaled mannitol than they were to histamine, and neutrophils may be important in determining this in patients taking steroids.

\footnotetext{
Acknowledgements. The use applications for mannitol described in this study are covered in the USA by Patent No. 5817028 and internationally by PCT/AU 95/00086. The patent is owned by the Central Sydney Area Health Service.
}

\section{References}

1. National Asthma Campaign. Asthma Management Handbook. South Melbourne, Victoria, Australia, National Asthma Campaign Ltd, 1998.
2. National Heart, Lung and Blood Institute. Guidelines for the Diagnosis and Management of Asthma. Bethesda, MD, National Institutes of Health, 1997 7/97. Report No. 97-4051.

3. Cai Y, Carty K, Henry RL, Gibson PG. Persistence of sputum eosinophilia in children with controlled asthma when compared with healthy children. Eur Respir J 1998; 11: 848-853.

4. Barnes PJ, Pedersen S, Busse WW. Efficacy and safety of inhaled corticosteroids. Am J Respir Crit Care Med 1998; 157: S1-S53.

5. Jatakanon A, Lim S, Kharitonov SA, Chung KF, Barnes PJ. Correlation between exhaled nitric oxide, sputum eosinophils, and methacholine responsiveness in patients with mild asthma. Thorax 1998; 53: 91-95.

6. Gibson PG, Wlodarczyk JW, Hensley MJ, et al. Epidemiological association of airway inflammation with asthma symptoms and airway hyperresponsiveness in childhood. Am J Respir Crit Care Med 1998; 158: 36-41.

7. Du Toit JL, Anderson SD, Jenkins CR, Woolcock AJ, Rodwell LT. Airway responsiveness in asthma: Bronchial challenge with histamine and $4.5 \%$ sodium chloride before and after budesonide. Allergy Asthma Proc 1997; 18: 7-14.

8. Pin I, Gibson PG, Kolendowicz R, et al. Use of induced sputum cell counts to investigate airway inflammation in asthma. Thorax 1992; 47: 25-29.

9. Gibson PG, Wong BJO, Hepperle MJE, et al. A research method to induce and examine a mild exacerbation of asthma by withdrawal of inhaled corticosteroid. Clin Exp Allergy 1992; 22: 525-532.

10. Booth H, Richmond I, Ward C, Gardiner PV, Harkawat R, Walters EH. Effect of high dose inhaled fluticasone propionate on airway inflammation in asthma. Am J Respir Crit Care Med 1995; 152: 45-52.

11. Massaro AF, Gaston B, Kita D, Fanta C, Stamler JS, Drazen JM. Expired nitric oxide levels during treatment of acute asthma. Am J Respir Crit Care Med 1995; 152: 800-803.

12. Kharitonov SA, Yates DH, Barnes PJ. Inhaled glucocorticoids decrease nitric oxide in exhaled air of asthmatic patients. Am J Respir Crit Care Med 1996; 153: 454 457.

13. American Thoracic Society. Standards for the diagnosis and care of patients with chronic obstructive pulmonary disease (COPD) and asthma. Am Rev Respir Dis 1987; 136: 225-244.

14. Knudson RJ, Lebowitz MD, Holberg CJ, Burrows B. Changes in the normal maximal expiratory flowvolume curve with growth and aging. Am Rev Respir Dis 1983; 127: 725-734.

15. Yan K, Salome C, Woolcock A. Rapid method for the measurement of bronchial responsiveness. Thorax 1983; 38: 760-765.

16. O'Connor G, Sparrow D, Taylor D, Segal M, Weiss S. Analysis of dose response curves to methacholine. An approach suitable for population studies. Am Rev Respir Dis 1987; 136: 1412-1417.

17. Peat JK, Salome CM, Berry G, Woolcock AJ. Relation of dose-response slope to respiratory symptoms in a population of Australian schoolchildren. Am Rev Respir Dis 1991; 144: 663-667.

18. Anderson SD, Spring J, Moore B, et al. The effect of inhaling a dry powder of sodium chloride on the airways of asthmatic subjects. Eur Respir J 1997; 10: 2465-2473. 
19. Salome CM, Roberts AM, Brown NJ, Dermand J, Marks GB, Woolcock AJ. Exhaled nitric oxide measurements in a population sample of young adults. Am J Respir Crit Care Med 1999; 159: 911916.

20. Pizzichini E, Pizzichini MMM, Efthimiadis A, Hargreave FE, Dolovich J. Measurement of inflammatory indices in induced sputum: effects of selection of sputum to minimize salivary contamination. Eur Respir J 1996; 9: 1174-1180.

21. Brand PLP, Duiverman EJ, Postma DS, et al. Peak flow variation in childhood asthma: relationship to symptoms, atopy, airways obstruction and hyperresponsiveness. Eur Respir J 1997; 10: 1242-1247.

22. Reddel HK, Salome CM, Peat JK, Woolcock AJ. Which index of peak expiratory flow is most useful in the management of stable asthma? Am J Resp Crit Care Med 1995; 151: 1320-1325.

23. Anderson SD, Brannan J, Spring J, et al. A new method for bronchial-provocation testing in asthmatic subjects using a dry powder of mannitol. Am J Respir Crit Care Med 1997; 156: 758-765.

24. Kips JC, Fahy JV, Hargreave FE, Ind PW, in't Veen JCCM. Methods for sputum induction and analysis of induced sputum: a method for assessing airway inflammation in asthma. Eur Respir J 1998; 11: Suppl. 26, 9s-12s.

25. Pavord ID, Pizzichini MMM, Pizzichini E, Hargreave FE. The use of induced sputum to investigate airway inflammation. Thorax 1997; 52: 498-501.

26. Hallsworth MP, Litchfield TM, Lee TH. Glucocorticoids inhibit granulocyte-macrophage colony-stimulating factor-1 and interleukin-5 enhanced in vitro survival of human eosinophils. Immunology 1992; 75: 382-385.

27. Crimi E, Spanevello A, Neri M, Ind PW, Rossi GA, Brusasco V. Dissociation between airway inflammation and airway hyperresponsiveness in allergic asthma. Am J Respir Crit Care Med 1998; 157: 4-9.

28. Wark PA, Gibson PG, Fakes K. Induced sputum eosinophils in the assessment of asthma and chronic cough. Respirology 2000; 5: 51-57.

29. Hargreave FE. Induced sputum for the investigation of airway inflammation: evidence for its clinical application. Can Respir J 1999; 6: 169-174.

30. Jatakanon A, Kharitonov S, Lim S, Barnes PJ. Effect of differing doses of inhaled budesonide on markers of airway inflammation in patients with mild asthma. Thorax 1999; 54: 108-114.

31. Dupont LJ, Rochette F, Demedts MG, Verleden GM. Exhaled nitric oxide correlates with airway hyperresponsiveness in steroid-naive patients with mild asthma. Am J Respir Crit Care Med 1998; 157: 894 898.

32. Sont JK, Han J, van Krieken JM, et al. Relationship between the inflammatory infiltrate in bronchial biopsy specimens and clinical severity of asthma in patients treated with inhaled steroids. Thorax 1996; 51: 496-502.

33. van Rensen ELJ, Straathof KCM, Veselic-Charvat MA, Zwinderman AH, Bel EH, Sterk PJ. Effect of inhaled steroids on airway hyperresponsiveness, sputum eosinophils, and exhaled nitric oxide levels in patients with asthma. Thorax 1999; 54: 403-408.

34. Lim S, Jatakanon A, Meah S, Oates T, Chung KF, Barnes PJ. Relationship between exhaled nitric oxide and mucosal eosinophilic inflammation in mild to moderately severe asthma. Thorax 2000; 55: 184 188.

35. Sterk PJ, Fabbri LM, Quanjer PH, et al. Airway responsiveness: Standardized challenge testing with pharmacological, physical and sensitizing stimuli in adults. Eur Respir J 1993; 6: Suppl. 16, S53-S83.

36. Britton J, Mortagy A, Tattersfield A. Histamine challenge testing: comparison of three methods. Thorax 1986; 41: 128-132.

37. Brannan JD, Anderson SD, Freed R, Leuppi JD, Koskela K, Chan HK. Nedocromil sodium inhibits responsiveness to inhaled mannitol in asthmatic subjects. Am J Respir Crit Care Med 2000; 161: 2096-2099.

38. Brannan JD, Anderson SD, Gomes K, King G, Seale JP, Chan HK. Histamine antagonist fexofenadine $\mathrm{HCl}$ decreases airway sensitivity to inhaled mannitol in subjects with asthma. Eur Respir J 2000; 16: Suppl. 31, 329s.

39. Brannan JD, Anderson SD, Gomes K, King G, Seale JP, Chan HK. Leukotriene antagonist montelukast sodium reduces time of recovery following challenge with inhaled mannitol without altering sensitivity. Eur Respir J 2000; 16: Suppl. 31, 372s-373s.

40. Brusasco V, Crimi E, Pellegrino R. Airway hyperresponsiveness in asthma: not just a matter of airway inflammation. Thorax 1998; 53: 992-998. 